\title{
Magnitudes and Determinants of Antenatal Care Utilization among Pregnant Women in East Africa: Evidence from Demographic and Health Surveys (DHS) from 2010 to 2018
}

\author{
Temam Beshir Raru ( $\nabla$ temam.b1@gmail.com ) \\ Haramaya University https://orcid.org/0000-0002-4389-3553 \\ Belay Negash \\ Haramaya University \\ Biruk Shalmenu \\ Haramaya University \\ Addisu Birhanu \\ Haramaya University \\ Lemma Demissie \\ Haramaya University \\ Nebiyu Bahiru \\ Haramaya University \\ Alemayehu Deressa \\ Haramaya University \\ Gebiso Roba \\ Haramaya University \\ Addisu Alemu \\ Haramaya University \\ Mohammed Yuya \\ Haramaya University \\ Galana Mamo \\ Haramaya University
}

\section{Research Article}

Keywords: Antenatal care utilization, East Africa, DHS, mixed effect

Posted Date: September 9th, 2021

DOI: https://doi.org/10.21203/rs.3.rs-885784/v1 
License: (c) (i) This work is licensed under a Creative Commons Attribution 4.0 International License. Read Full License 


\section{Abstract}

Introduction: The use of antenatal care (ANC) plays a major role in minimizing maternal and child mortality through effective and appropriate screening, preventive, or treatment intervention. Despite the fact that almost all of the pregnancy-related mortalities are largely preventable through adequate use of ANC, Sub-Saharan Africa (SSA) particularly East African Countries continues to share the largest share of global maternal, and newborn mortality. Therefore, this study aimed to estimate the overall magnitude and determinants of ANC utilization in the 11 East Africa Countries from 2010 to 2018 using recent Demographic and Health Surveys (DHS)

Methods: A secondary data analysis was done based on DHS from 2010 to 2018 in the 11 East African Countries. A total weighted sample of 89,991 women who gave birth in the 5 years preceding each country's DHS survey were included in this study. Data processing and analysis were performed using STATA 15 software. Multilevel mixed effect logistic regression model was fitted. Model comparison was done based on Akaike and Bayesian Information Criteria (AIC and BIC). Variables with a p-value $\leq 0.05$ were declared as significant determinants of ANC utilization.

Results: The magnitude of ANC utilization in East African Countries was 53.03\% (95\% Cl: 52.70, 53.35) with the highest ANC utilization in Kenya (57.64\%) and the lowest ANC utilization in Comoros (48.99\%). In the multivariable multilevel logistic regression model; age 20-24 (Adjusted Odds Ratio (AOR) $=1.25 ; 95 \%$ $\mathrm{Cl} ; 1.17-1.34), 25-29 \mathrm{AOR}=1.47 ; 95 \% \mathrm{Cl}$ 1.37-1.58), 30-34 (AOR = 1.58; 95\% Cl; 1.47-1.71), 35-39 (AOR = $1.63 ; 95 \% \mathrm{Cl} ; 1.50-1.77), 40-44(\mathrm{AOR}=1.64 ; 95 \% \mathrm{Cl} ; 1.49-1.81), 45-49$ (AOR $=1.71 ; 95 \% \mathrm{Cl} ; 1.51-1.93)$, primary education $(\mathrm{AOR}=1.24 ; 95 \% \mathrm{Cl} ; 1.18-1.31)$, richest wealth index $(\mathrm{AOR}=1.57 ; 95 \% \mathrm{Cl} ; 1.47-1.67)$, being in rural resident $(\mathrm{AOR}=0.93 ; 95 \% \mathrm{Cl} ; 0.88,0.98)$, have media exposure $(\mathrm{AOR}=1.11 ; 95 \% \mathrm{Cl} ; 1.07$ $1.15)$, and being a Zimbabwe resident $(A O R=2.87 ; 95 \% \mathrm{Cl} ; 2.55-3.23)$ were among factors that are significantly associated with ANC utilization.

Conclusion: ANC utilization was low in the East Africa countries. Age, women education, wealth index, birth order, residence, media exposure and living countries were major determinants of ANC utilization. It would be useful to increase financial support strategies that enables mothers from poor households to use health services will be advantageous. To increase women's understanding of the significance of ANC utilization, health education targeting mothers with no education is very crucial.

\section{Introduction}

Globally, about 303,000 women died in 2015 because of pregnancy and childbirth complications. Most of these deaths come from poor countries, and there is a huge disparity as compared to the developed countries. For a woman living in Sub-Saharan Africa, the lifetime risk of maternal mortality is over 47 times greater than for a woman living in the United States (US) (1). In 2013, the World Health Organization (WHO) and U.S. Agency for International Development (USAID) representatives proposed an 
energetic but accomplished target in the Lancet Global Health to decrease the global mean maternal mortality ratio (MMR) to less than 50 per 100,000 live births by 2035 (1).

The use of antenatal care (ANC) plays a major role in minimizing maternal and child mortality through effective and appropriate screening, preventive, or treatment interventions (2). In low and middle income countries ANC services make significant improvement in birth outcomes and long-term reductions of child mortality and malnutrition (3). Even if, many African countries are still struggling to achieve high coverage of four ANC visits, eight ANC contacts are suggested by WHO (4).

By reducing stillbirths and neonatal deaths, ANC had a direct improvement on the survival and health of babies and had indirect improvement by providing an entry point for health encounters with the woman at a critical point in the continuum of care (5). The goal of the ANC package is to prepare for birth and to avoid, identify, mitigate, or treat health issues that affect mothers and babies during pregnancy (5). Burundi, Ethiopia, Comoros, Uganda, Rwanda, Tanzania, Mozambique, Zimbabwe, Kenya, Zambia, and Malawi reported poor accessibility and affordability of maternal health care services (6).

Sub-Saharan Africa (SSA) accounts for 19 of the 20 countries with the highest maternal mortality rates (7). The study conducted in Ethiopia stated that individual level factors such as religion, level of education, distance from health facility and community level factors like residence, country, and level of literacy rate was associated with ANC utilization (8). The studies from Nigeria, Uganda, and Tanzania reported that educational status and occupation had a significant effect on ANC utilization (9-11). Other studies conducted in Bangladesh reported that mass media and wealth index plays an important role for the ANC utilization (12).

Despite the fact that almost all of the pregnancy-related mortalities are largely preventable through adequate use of ANC, SSA particularly East African Countries continues to share the largest share of global maternal, and newborn mortality. As for our literature quest, there is limited evidence in East African countries about the magnitude and factors associated with ANC utilization. Therefore, this study aimed to estimate the overall magnitude and determinants of ANC utilization in the 11 East Africa Countries from 2010 to 2018 using recent Demographic and Health Surveys (DHS).

\section{Methods}

\section{Study setting and data source}

The United Nation (UN) Statistics Division has subdivided the African continent into five regions. Among these countries, East Africa is the one largest region that includes 19 countries (Burundi, Comoros, Djibouti, Ethiopia, Eritrea, Kenya, Madagascar, Malawi, Mauritius, Mozambique, Reunion, Rwanda, Seychelles, Somalia, Somaliland, Tanzania, Uganda, Zambia, and Zimbabwe). This study was a secondary data analysis based on Demographic and Health Surveys (DHS). From these 19 East Africa countries, 13 countries have DHS data whereas 6 (Djibouti, Somalia, Somaliland, Seychelles and Mauritius, Reunion). Among these 13 countries that have DHS data, 2 countries have DHS data that was 
conducted before 2010 (Eritrea-2002 and Madagascar-2008). In this study, we included 11 counties DHS data that was conducted after 2010.

The data of these 11 East Africa countries were accessed from the demography heath survey (DHS) program official database www.measuredhs.com, after authorization was granted through online request by explaining the goal of our study. We used the individual Record (IR file) data set and extracted the dependent and independent variables. To collect knowledge that is comparable across countries in the world, the DHS program adopts standardized methods involving uniform questionnaires, manuals, and field procedures. DHS is a nationally representative household survey that offers data from a wide variety of population, health, and nutrition tracking and effect assessment measures with face-to-face interviews of women aged 15 to 49. Stratified, multi-stage, random sampling is used in the surveys. In each country, information was obtained from qualified women aged 15 to 49 years. Detailed survey techniques and methods of sampling used to collect data have been recorded elsewhere (13).

\section{Variables}

\section{Outcome variable}

The response (outcome) variable of this study was ANC utilization. The response variable is binary and it is coded as 1 if women received ANC from skilled health care provider (Doctors, Midwives, Nurses, and Health officers) at least four times and 0 otherwise.

\section{Independent variables}

Based on different literatures, two types of independent variables were considered. Individual level and community-level variables. Community-level variables include literacy rate, country and residence. The individual level variables are age, level of education, distance from health facility, birth order, mass media, and wealth index.

\section{Data processing and management}

Data processing and analysis were performed using STATA 15 software. The data were weighted using sampling weight, primary sampling unit and strata before any statistical analysis to restore the representativeness of the survey and to tell the STATA to take into account the sampling design when calculating standard errors to get reliable statistical estimates. Cross tabulations and summary statistics were conducted to describe the study population.

\section{Statistical analysis}


Since the DHS data has a hierarchical nature, women within a cluster may be more similar to each other than women in the other cluster. Due to this, the assumption of independence of observations and equal variance across clusters might be violated. Therefore, an advanced statistical model is required to take into account the between cluster variability to get a reliable standard error and unbiased estimate.

Furthermore, by taking into account the dichotomous nature of the outcome variable, multilevel mixed effect logistic regression was fitted. Model comparison was done based on Akaike and Bayesian Information Criteria (AIC and BIC). Mixed effect model with the lowest Information Criteria (AIC and BIC) was selected.

The individual and community level variables associated with ANC utilization were checked independently in the bi-variable multilevel mixed-effect logistic regression model and variables which were statistically significant at p-value 0.20 in the bi-variable multilevel mixed-effects logistic regression analysis were considered for the final individual and community level model adjustments. In the multivariable multilevel mixed-effect analysis, variables with a $p$-value $\leq 0.05$ were declared as significant determinants of ANC utilization. Intra class correlation coefficient (ICC) were used to check whether or not multilevel model is appropriate and how much of the overall variation in the response is explained by clustering.

Four models were fitted. The first was the null model that did not include exposure variables which was used to verify community variance and provide evidence to assess random effects at the community level. Then model I was the multivariable model adjustment for individual-level variables and model II was adjusted for community-level factors. In model III, the outcome variable was equipped with potential candidate variables from both individual and community level variables.

The fixed effects (a measure of association) were used to estimate the association between the ANC utilization and explanatory variables and expressed as odds ratio with $95 \%$ confidence interval. Regarding the measures of variation (random-effects), Community-level variance with standard deviation and intra-cluster correlation coefficient (ICC) was used.

\section{Results}

\section{Socio-Demographic, Economic and Maternal Characteristics and Magnitude of ANC Utilization}

A total of 89,991 women who gave birth in the 5 years preceding each country's DHS survey were included in this study. Majority of women lie in the age group of 25-29. Most of the women included were from Kenya 14407.99(16.01\%) and the smallest number of women included from Comoros 2059.93(2.29\%). The magnitude of ANC utilization in East African Countries was 53.03\% (95\% Cl: 52.70, 53.35) with the highest ANC utilization in Kenya (57.64\%) and the lowest ANC utilization in Comoros 
(48.99\%). Three-fourth of the women were from rural residents $67794.60(75.34 \%)$ and $66.69 \%$ of the women had a media exposure (Table 1).

\section{Determinants of ANC Utilization in East Africa Result of the random effects}

The results of the null model revealed that there was statistically significant variability in the odds of ANC utilization with community variance $63.97 \%$ and the ICC in the null model suggested that $16.27 \%$ of the total variability in the ANC utilization was ascribed to the differences between communities. In the full model (model adjusted for both individual and community-level factors) community variance $=0.37$; $\mathrm{SE}$ 0.01 , remained significant but reduced and $10.12 \%$ of the total variance of ANC utilization can be ascribed to the community (Table 2).

\section{Result of the fixed effects}

The model with smaller AIC and BIC was best fit the data and the interpretation of the fixed effects was based on this model. Model III was adjusted for both individual and community-level factors and this model fits the data well. In the multivariable analysis respondent's age group, place of residence, respondent's education, wealth index, birth interval, media exposure, living Country were significantly associated with the ANC utilization in the East Africa at $5 \%$ level of significance.

The odds of ANC utilization were $1.25(\mathrm{AOR}=1.25 ; 95 \% \mathrm{Cl} ; 1.17-1.34)$ times higher among the women in the age group of $20-24,1.47(\mathrm{AOR}=1.47 ; 95 \% \mathrm{Cl} ; 1.37-1.58)$ times higher among the women in the age group of $25-29,1.58(\mathrm{AOR}=1.58 ; 95 \% \mathrm{Cl} ; 1.47-1.71)$ times higher among the women in the age group of $30-34,1.63(\mathrm{AOR}=1.63 ; 95 \% \mathrm{Cl} ; 1.50-1.77)$ times higher among the women in the age group of 35-39, $1.64(\mathrm{AOR}=1.64 ; 95 \% \mathrm{Cl} ; 1.49-1.81)$ times higher among the women in the age group of 40-44, 1.71 $(A O R=1.71 ; 95 \% \mathrm{Cl} ; 1.51-1.93)$ times higher among the women in the age group of 45-49 as compared to the women in the age group of 15-19. Women who are richest were 1.57 times more likely to utilize ANC than women who are poorest $(A O R=1.57 ; 95 \% \mathrm{Cl} ; 1.47-1.67)$. The odds of ANC utilization are reduced by $7 \%$ among rural women $(\mathrm{AOR}=0.93 ; 95 \% \mathrm{Cl} ; 0.88,0.98)$ as compared to women residing in urban areas. Women who have a media exposure are 1.11 times (AOR $=1.11 ; 95 \% \mathrm{Cl} ; 1.07-1.15)$ more likely to have ANC utilization than their counterparts. Pregnant women living in the following East African Countries are more likely to have ANC utilizations, Kenya ( $\mathrm{AOR}=1.11 ; 95 \% \mathrm{Cl}$; $1.02-1.21)$, Mozambique $(A O R=1.19 ; 95 \% \mathrm{Cl} ; 1.08-1.32)$, Uganda $(\mathrm{AOR}=1.47 ; 95 \% \mathrm{Cl} ; 1.33-1.61)$, Zambia $(\mathrm{AOR}=1.77 ; 95 \% \mathrm{Cl}$; 1.59-1.96), Zimbabwe $(A O R=2.87 ; 95 \% \mathrm{Cl} ; 2.55-3.23)$, than women living in Burundi (Table 2).

\section{Discussion}

The overall aim of this study was to investigate the pooled magnitude and predictors of ANC utilization in the 11 East Africa Countries from 2010 to 2018 using recent Demographic and Health Surveys dataset. The pooled magnitude of ANC utilization in East African Countries was $53.03 \%(95 \%$ Cl: $52.70,53.35)$ 
with the highest ANC utilization in Kenya (57.64\%) and the lowest ANC utilization in Comoros (48.99\%). This finding is comparable with study conducted in Nepal (14), and study conducted on Analysis of National Survey data in seven countdown countries (15), but lower than finding reported at Nigeria National Hospital (16), Kumbotso village, Northern Nigeria (17), among mothers in Uganda (18) and Systematic review and Meta-analysis conducted in Ethiopia (19). This might be attributed to difference in sample size, socioeconomic and sociocultural aspect of the society.

The odds of ANC utilization were higher among women of older age groups (45-49) compared to women of younger age groups (15-19). This finding is supported by study conducted on Determinants of ANC in sub-Saharan Africa: A systematic review (20), Social determinants of ANC service use in Ethiopia: Changes over a 15-year span (21), and Determinants of ANC visits and their impact on the choice of birthplace among mothers in Uganda: a systematic review (18). This might be due to as the age of the mother's increases, they might have a better knowledge, understanding and experience of pregnancy and pregnancy related complications (22).

The odds of ANC utilization was higher among women with better educational status, similar finding was reported by, Understand Factors Influencing Accessibility of Pregnant Women to Antenatal Care Services Accessibility factors (22), and An evidence from demographic health survey 2016(23) Evidence from Ethiopian demographic health surveys (24). This might be because women with better educational status are capable of identifying danger signs and easily understand the adverse outcome of avoiding the recommended ANC service.

Women who were richest were more likely to utilize ANC than women who are poorest. This finding is consistent with study conducted in Ethiopia (21), Analysis of national survey data in seven countdown countries (15), Determinants of ANC in sub-Saharan Africa: A systematic review (20), and populationbased study using the DHS data (14). This is because of women in better socioeconomic status have more ability to pay for both direct and indirect health care costs.

The odds of ANC utilization were negatively associated with women living in rural areas. This finding is similar with the findings of Determinants of ANC in sub-Saharan Africa: A systematic review (20), study conducted in Ethiopia (21), and Factors affecting utilization of ANC in Ethiopia: A systematic review and meta analysis (19). This might due to the fact that most of the health care facilities are easily accessible in urban areas than rural areas. Hence, make women living in rural areas less likely use ANC services.

Women exposed to media were more likely had ANC utilization than their counterparts. This finding is in line with population-based study using the DHS data (14), Factors affecting the utilization of ANC in developing countries: Systematic review of the literature (25) and Factors affecting utilization of ANC in Ethiopia: A systematic review and meta analysis (9). This may be explained by exposure to information may enhance the advantage and disadvantage of using health care services.

Birth rank was negatively associated with ANC utilization among women's 5th birth. This finding is supported by study conducted in Ethiopia (21), Analysis of National Survey data in seven countdown 
countries (15) and An evidence from demographic health survey 2016(23) Evidence from Ethiopian demographic health surveys (24).

\section{Strengths and Limitation of the study}

Pertaining to the strengths, the dataset used in this study was obtained from nationally representative survey and the variables in the 11 East Africa DHS dataset were the same hence, comparable across all countries. The data were pooled together to create a large sample size and increase the generalizability of ANC utilization reported within 5 years preceding each country survey which ranges from 2010 to 2018 and was able to identify the significant determinants of ANC utilization across the 11 East African Countries to inform policymakers and planners for their intervention to prioritize.

With regard to limitations, the data was gathered based on self-report from mothers within 5 years prior to the survey and this may be a possible source of recall and misclassification bias. In East Africa, six countries had no DHS data and the result of this study may not representative of the entire East Africa country.

\section{Conclusions}

ANC utilization was low in the East Africa countries. The influences of several covariates on the evolution of the number of seizure attacks were identified. Among these, age, women education, wealth index, birth order, residence, media exposure and living countries were major determinants of ANC utilization. It would be useful to increase financial support strategies that enables mothers from poor households to use health services will be advantageous. To increase women's understanding of the significance of ANC utilization, health education targeting mothers with no education is very crucial.

\section{Declarations}

\section{Ethics approval and consent to participate}

The study was based on secondary analysis of existing DHS data with all identifying information removed. Permission for data access was obtained from measure demographic and health survey through an online request from www.measuredhsprogram.com by explaining the goal of our study.

\section{Consent to publication}

Not applicable

\section{Competing interests}

There is no competing of interests related to this work.

\section{Funding}


No funding was obtained for this study.

\section{Authors' contributions}

TB, BS and BN conceived the study, variable extraction, data cleaning, analysis, interpretation, drafted the final report write up, prepared the manuscript and reviewed the article. TB, $B S, B N, G M, A B, L D, N B, A D, A A$, $M T, M Y$, and GR participated in data analysis, involved in report write up, and extensively reviewed the article. All authors read and approved the final manuscript.

\section{Acknowledgments}

We greatly acknowledge measure DHS program for granting access to the East African DHS data sets.

\section{Data availability and materials}

Data is available online and you can access it from www.measuredhs.com.

\section{Abbreviations}

AIC

Akaike Information Criteria, ANC:Antenatal Care, AOR:Adjusted Odds Ratio, BIC:Bayesian Information Criteria, DHS:Demographic and Health Survey, ICC:Intra-class Correlation Coefficient, SSA:Sub-Saharan Africa, WHO:World Health Organization.

\section{References}

1. USAID. Ending Preventable Maternal Mortality [Internet]. 2014. Available from: https://www.usaid.gov/sites/default/files/documents/1864/MCHVision.pdf

2. Campbell OM GWGLmss. Strategies for reducing maternal mortality: getting on with what works. Lancet. 2006;368(9543):1284-99.

3. Kuhnt J, Vollmer S. Antenatal care services and its implications for vital and health outcomes of children: Evidence from 193 surveys in 69 low-income and middle-income countries. BMJ Open. 2017;7(11):1-7.

4. Organization $\mathrm{WH}$. WHO recommendations on antenatal care for a positive pregnancy experience [Internet]. 2016. Available from: https://www.who.int/publications/i/item/9789241549912

5. Clavagnier I. Antenatal care. Rev Infirm. 2012;(185):45-6.

6. Alvarez JL, Gil R, Hernández V, Gil A. Factors associated with maternal mortality in Sub-Saharan Africa: An ecological study. BMC Public Health. 2009;9:1-8.

7. Tessema ZT, Animut Y. Spatial distribution and determinants of an optimal ANC visit among pregnant women in Ethiopia: Further analysis of 2016 Ethiopia demographic health survey. BMC Pregnancy Childbirth. 2020;20(1):1-13. 
8. Adewuyi EO, Auta A, Khanal V, Bamidele OD, Akuoko CP, Adefemi K, et al. Prevalence and factors associated with underutilization of antenatal care services in Nigeria: A comparative study of rural and urban residences based on the 2013 Nigeria demographic and health survey. PLoS One. 2018;13(5):1-21.

9. Kawungezi PC, Akiibua D, Aleni C, Chitayi M, Kazibwe A, Sunya E, et al. Multi-Center Study in Upcountry Areas of Uganda. Open J Prev Med. 2015;5(3):132-42.

10. Gupta S, Yamada G, Mpembeni R, Frumence G, Callaghan-Koru JA, Stevenson R, et al. Factors associated with four or more antenatal care visits and its decline among pregnant women in Tanzania between 1999 and 2010. PLoS One. 2014;9(7).

11. Ali N, Sultana M, Sheikh N, Akram R, Mahumud RA, Asaduzzaman M, et al. Predictors of Optimal Antenatal Care Service Utilization Among Adolescents and Adult Women in Bangladesh. Heal Serv Res Manag Epidemiol. 2018;5:233339281878172.

12. Demographic T PH. Guide to DHS Statistics.

13. Joshi C, Torvaldsen S, Hodgson R, Hayen A. Factors associated with the use and quality of antenatal care in Nepal: A population-based study using the demographic and health survey data. BMC Pregnancy Childbirth. 2014;14(1):1-11.

14. Saad-Haddad G, DeJong J, Terreri N, Restrepo-Méndez MC, Perin J, Vaz L, et al. Patterns and determinants of antenatal care utilization: Analysis of national survey data in seven countdown countries. J Glob Health. 2016;6(1).

15. Olayinka A, Joel A, Bukola D. Factors influencing utilization of antenatal care services among pregnant women in Ife Central Lga, Osun State Nigeria National Hospital Abuja, Nigeria. Adv Appl Sci Res. 2012;3(3):1309-15.

16. Kabir M, Iliyasu Z, Abubakar IS, Sani AA. Determinants of utilization of antenatal care services in Kumbotso village, Northern Nigeria. Trop Doct. 2005;35(2):110.

17. Atuhaire S, Mugisha JF. Determinants of antenatal care visits and their impact on the choice of birthplace among mothers in Uganda: a systematic review. Obstet Gynecol Int J. 2020;11(1):77-81.

18. Tekelab T, Chojenta C, Smith R, Loxton D. Factors affecting utilization of antenatal care in Ethiopia: A systematic review and metaanalysis. PLoS One. 2019;14(4):1-24.

19. Okedo-Alex IN, Akamike IC, Ezeanosike OB, Uneke CJ. Determinants of antenatal care utilisation in sub-Saharan Africa: A systematic review. BMJ Open. 2019;9(10):1-14.

20. Ousman SK, Mdala I, Thorsen VC, Sundby J, Magnus JH. Social determinants of antenatal care service use in ethiopia: Changes over a 15-year span. Front Public Heal. 2019;7(JUN):1-10.

21. Ayalew TW, Nigatu AM. Focused antenatal care utilization and associated factors in Debre Tabor Town, northwest Ethiopia, 2017. BMC Res Notes [Internet]. 2018;11(1):1-6. Available from: https://doi.org/10.1186/s13104-018-3928-y

22. Tsegaye B, Ayalew M. Prevalence and factors associated with antenatal care utilization in Ethiopia: An evidence from demographic health survey 2016. BMC Pregnancy Childbirth. 2020;20(1):1-9. 
23. Yeneneh A, Alemu K, Dadi AF, Alamirrew A. Spatial distribution of antenatal care utilization and associated factors in Ethiopia: Evidence from Ethiopian demographic health surveys. BMC Pregnancy Childbirth. 2018;18(1):1-12.

24. Simkhada B, Van Teijlingen ER, Porter M, Simkhada P. Factors affecting the utilization of antenatal care in developing countries: Systematic review of the literature. J Adv Nurs. 2008;61(3):244-60.

25. 25. Simkhada B, Van Teijlingen ER, Porter M, Simkhada P. Factors affecting the utilization of antenatal care in developing countries: Systematic review of the literature. J Adv Nurs. 2008;61(3):244-60.

\section{Tables}

Table 1: Socio-demographic, economic, and maternal characteristic respondents in the 11 East Africa Countries from 2010 to 2018 with its distribution of ANC utilization among each category 


\begin{tabular}{|c|c|c|c|}
\hline Variable & $\begin{array}{l}\text { Weighted } \\
\text { Frequency }\end{array}$ & Percentage(\%) & $\begin{array}{l}\% \text { of } 4 \text { or more ANC } \\
\text { visit }\end{array}$ \\
\hline \multicolumn{4}{|l|}{ ANC Utilization } \\
\hline No & 42271.84 & 46.97 & \\
\hline Yes & 47718.70 & 53.03 & 100 \\
\hline \multicolumn{4}{|l|}{ Age } \\
\hline $15-19$ & 6267.58 & 6.96 & 49.93 \\
\hline $20-24$ & 21440.12 & 23.82 & 53.68 \\
\hline $25-29$ & 23046.69 & 25.61 & 54.69 \\
\hline $30-34$ & 18534.30 & 20.60 & 53.77 \\
\hline 35-39 & 12590.51 & 13.99 & 51.80 \\
\hline $40-44$ & 6140.31 & 6.82 & 49.66 \\
\hline $45-49$ & 1971.02 & 2.19 & 47.47 \\
\hline \multicolumn{4}{|l|}{ Place of residence } \\
\hline Urban & 22195.94 & 24.66 & 62.82 \\
\hline Rural & 67794.60 & 75.34 & 49.82 \\
\hline \multicolumn{4}{|l|}{ Women level Education } \\
\hline No education & 19722.14 & 21.92 & 40.03 \\
\hline Primary & 47341.74 & 52.61 & 52.13 \\
\hline Secondary & 19275.54 & 21.42 & 63.63 \\
\hline Higher & 3651.12 & 4.06 & 78.83 \\
\hline \multicolumn{4}{|l|}{ Sex of house hold head } \\
\hline Male & 67531.28 & 75.04 & 52.70 \\
\hline Female & 22459.26 & 24.96 & 53.99 \\
\hline \multicolumn{4}{|l|}{ Literacy } \\
\hline Cannot read at all & 32071.05 & 35.65 & 44.78 \\
\hline \multirow{2}{*}{$\begin{array}{l}\text { Able to read only parts of } \\
\text { sentence }\end{array}$} & 8395.03 & 9.33 & 52.78 \\
\hline & 49270.33 & 54.77 & 58.44 \\
\hline No card with required language & 128.52 & 0.14 & 46.79 \\
\hline Blind/visually impaired & 88.64 & 0.10 & 59.75 \\
\hline
\end{tabular}




\begin{tabular}{|c|c|c|c|}
\hline \multicolumn{4}{|l|}{ Wealth index } \\
\hline Poorest & 19844.20 & 22.05 & 45.92 \\
\hline Poorer & 18608.99 & 20.68 & 49.11 \\
\hline Middle & 17303.96 & 19.23 & 51.59 \\
\hline Richer & 17299.29 & 19.22 & 55.24 \\
\hline Richest & 16934.09 & 18.82 & 64.86 \\
\hline \multicolumn{4}{|c|}{ Distance to health facility } \\
\hline Big problem & 35094.72 & 42.57 & 48.35 \\
\hline Not big problem & 47352.44 & 57.43 & 55.83 \\
\hline \multicolumn{4}{|l|}{ Birth order } \\
\hline 1 & 20313.05 & 22.57 & 58.06 \\
\hline $2-4$ & 43915.75 & 48.80 & 54.28 \\
\hline$>=5$ & 25761.74 & 28.63 & 46.92 \\
\hline \multicolumn{4}{|l|}{ Media Exposure } \\
\hline No Exposure & 29979.78 & 33.31 & 46.53 \\
\hline Exposure & 60010.75 & 66.69 & 56.27 \\
\hline \multicolumn{4}{|l|}{ Country } \\
\hline Burundi & 8941.63 & 9.94 & 49.26 \\
\hline Ethiopia & 7589.11 & 8.43 & 31.82 \\
\hline Kenya & 14407.99 & 16.01 & 57.64 \\
\hline Comoros & 2059.93 & 2.29 & 48.99 \\
\hline Malawi & 13515.40 & 15.02 & 50.58 \\
\hline Mozambique & 7874.21 & 8.75 & 50.64 \\
\hline Rwanda & 6059.00 & 6.73 & 43.96 \\
\hline Tanzania & 7078.56 & 7.87 & 50.69 \\
\hline Uganda & 10152.35 & 11.28 & 59.89 \\
\hline Zambia & 7324.73 & 8.14 & 63.50 \\
\hline Zimbabwe & 4987.62 & 5.54 & 75.73 \\
\hline
\end{tabular}

Table 2: Multivariable multilevel mixed-effect logistic regression analysis of factors associated with ANC utilization in East Africa countries from 2010 to 2018 


\begin{tabular}{|c|c|c|c|c|}
\hline \multirow[t]{2}{*}{ Variables } & \multicolumn{4}{|l|}{ Models } \\
\hline & $\begin{array}{l}\text { Null Model } \\
\text { AOR(95\%Cl) }\end{array}$ & $\begin{array}{l}\text { Model I } \\
\text { AOR(95\%Cl) }\end{array}$ & $\begin{array}{l}\text { Model II } \\
\text { AOR(95\%Cl) }\end{array}$ & $\begin{array}{l}\text { Model III } \\
\text { AOR(95\%Cl) }\end{array}$ \\
\hline \multicolumn{5}{|l|}{ Age } \\
\hline $15-19$ & & 1 & & 1 \\
\hline $20-24$ & & $1.21(1.13,1.29)$ & & $1.25(1.17,1.34)$ * \\
\hline $25-29$ & & $1.38(1.29,1.48)$ & & $1.47(1.37,1.58)^{*}$ \\
\hline $30-34$ & & $1.49(1.38,1.61)$ & & \multirow{2}{*}{$1.58(1.47,1.71)^{*}$} \\
\hline $35-39$ & & $1.53(1.41,1.66)$ & & \\
\hline $40-44$ & & $1.55(1.41,1.71)$ & & $1.63(1.50,1.77)$ * \\
\hline \multirow[t]{2}{*}{$45-49$} & & $1.61(1.42,1.82)$ & & $1.64(1.49,1.81) *$ \\
\hline & & & & $1.71(1.51,1.93)$ * \\
\hline \multicolumn{5}{|c|}{$\begin{array}{l}\text { Women level of } \\
\text { Education }\end{array}$} \\
\hline \multicolumn{5}{|c|}{ No education } \\
\hline Primary & & 1 & & 1 \\
\hline Secondary & & $1.38(1.33,1.44)$ & & $1.24(1.18,1.31)$ * \\
\hline \multirow{2}{*}{ Higher } & & $1.79(1.69,1.89)$ & & $1.41(1.32,1.51)$ * \\
\hline & & $3.32(3.00,3.67)$ & & $2.65(2.38,2.96)$ * \\
\hline \multicolumn{5}{|c|}{$\begin{array}{l}\text { Sex of house hold } \\
\text { head }\end{array}$} \\
\hline مامج & & 1 & & 1 \\
\hline Female & & $0.97(0.94,1.00)$ & & $0.95(0.92,1.01)$ \\
\hline \multicolumn{5}{|c|}{ Wealth index } \\
\hline Poorest & & 1 & & 1 \\
\hline Poorer & & $1.16(1.11,1.22)$ & & $1.15(1.09,1.20)$ * \\
\hline Middle & & $1.24(1.18,1.30)$ & & $1.22(1.17,1.28)$ * \\
\hline Richer & & $1.31(1.24,1.37)$ & & $1.27(1.20,1.34)$ * \\
\hline Richest & & $1.58(1.49,1.67)$ & & $1.57(1.47,1.67)$ * \\
\hline \multicolumn{5}{|l|}{ Birth order } \\
\hline 1 & & 1 & & 1 \\
\hline
\end{tabular}




$\begin{array}{lll}2-4 & 0.82(0.78,0.85) & 0.78(0.75,0.82) \text { * } \\ >=5 & 0.65(0.62,0.69) & 0.62(0.58,0.65)\end{array}$ *

\section{Place of residence}

Urban

Rural

\section{Literacy}

Cannot read at all

Able to read only parts

Able to read whole

No card

Blind/visually impaired

\section{Media Exposure}

No Exposure

Exposure
1

$0.70(0.67,0.73)$
1

$0.93(0.88,0.98)$ *
1

$1.17(1.11,1.23) \quad 1.02(0.98,1.08)$

$1.33(1.27,1.37)$

$1.14(0.84,1.55)$

$1.64(1.04,2.58)$
$1.01(0.96,1.06)$

$1.01(0.74,1.38)$

$1.45(0.92,2.28)$ *

\section{Country}

Burundi

Ethiopia

1

1

$1.24(1.19,1.28)$

1.11(1.07,1.15)

Kenya

Comoros

Malawi

Mozambique

Rwanda

Tanzania

Uganda

Zambia

Zimbabwe
1

$0.65(0.59,0.72)$

1.07(0.99,1.17)

$0.98(0.85,1.13)$

1.03(0.95,1.13)

1.19(1.08,1.32)

$0.70(0.63,0.78)$

$0.92(0.83,1.02)$

$1.51(1.37,1.66)$

$1.86(1.68,2.06)$

$3.03(2.69,3.41)$
1

$0.61(0.55,0.67)^{*}$

$1.11(1.02,1.21)$ * $0.97(0.85,1.12)$ $0.99(0.91,1.08)$ $1.19(1.08,1.32)$ * $0.68(0.61,0.76)$ * $0.95(0.86,1.05)$ $1.47(1.33,1.61)$ * $1.77(1.59,1.96)$ * $2.87(2.55,3.23)$ * 


$\begin{array}{lllll}\text { Community } & 0.6397(0.019) & 0.4847(0.016) & 0.4007(0.014) & 0.3704(0.014) \\ \text { Variance } & 16.27 \% & 12.84 \% & 10.85 \% & 10.12 \% \\ \text { ICC } \% & & & & \end{array}$

Model Comparison

AIC

118892.7

116891.2

116883.4

117060.4

117052.6

115820.1

118911.5

$\mathrm{BIC}$

NB: * = Significant at P-value $<0.05$ ICC = Intra-class Correlation Coefficient, AOR=Adjusted Odds Ratio, $\mathrm{ANC}=$ Antenatal Care, $\mathrm{AIC}=$ Akaike Information Criteria, $\mathrm{BIC}=$ Bayesian Information Criteria 